\title{
South America
}

National Cancer Institute

\section{Source}

National Cancer Institute. South America. NCI Thesaurus. Code C26277.

South America is a continent of the western hemisphere with most of its area in the southern hemisphere. It is situated between the Pacific Ocean and the Atlantic Ocean and is attached at the north to North America by the Isthmus of Panama. 